\title{
Nobel Symposium on Free Electron Laser Research
}

\author{
Mats Larsson \\ Department of Physics, AlbaNova University Center, Stockholm University, Stockholm SE-106 91, Sweden; \\ mats.larsson@fysik.su.se; Tel.: +46-8-5537-8647 \\ Academic Editor: Kiyoshi Ueda \\ Received: 5 April 2017; Accepted: 17 April 2017; Published: 18 April 2017
}

\begin{abstract}
This meeting report describes the Nobel Symposium on Free Electron Laser Research, which was organized in Sigtuna, Sweden, 14-18 June 2015.
\end{abstract}

Keywords: free electron laser; X-rays; Nobel Symposia

\section{Introduction}

The Nobel Foundation initiated Nobel Symposia in 1965. According to the Nobel Symposia Instructions, "The symposium should be devoted to scientific or scholarly disciplines related to the Nobel Prize areas." Before a symposium is approved, the Nobel Committees are consulted. Two characteristics of a Nobel Symposium is a limited number of participants (30-40) and a chance for a limited number of younger researchers to follow the symposium as observers.

The local symposium committee, in the present case consisting of Mats Larsson, Ingolf Lindau, and Joseph Nordgren, all members of the Royal Swedish Academy of Sciences, is requested to have an international committee to assist in composing the scientific programme. The international committee consisted of Massimo Altarelli (European XFEL), Nora Berrah (UConn), John Galayda (SLAC), and Jon Marangos (Imperial College London).

The Nobel Symposium took place at Sigtuna outside Stockholm between 14 and 18 June 2015.

\section{Aim and Scope and Presentations}

The programme was divided into seven areas: atomic and molecular optical physics (AMO), life science, matter at extreme conditions, time-resolved phenomena, condensed matter physics, nonlinear processes, and accelerator physics. Each speaker was allotted an hour including questions, and the discussions were lively!

The main focus was of course on the impressive scientific development of $X$-ray free electron lasers (FELs), but there were also a few talks devoted to long wavelength FELs. The full programme including links to the talks as PDF files is available here: http:/ / agenda.albanova.se/conferenceDisplay.py? confId $=4905$.

\section{Conclusions}

The invited speakers provide a very good overview of the cutting edge research on free electron lasers, related theory work, and both their history and their future.

As a curiosity, it can be mentioned that the conference photo displayed on the symposium webpage was initiated by the guest editor of this volume, Kiyoshi Ueda, who was also invited to speak at the symposium.

For several participants, this was the first time they had the opportunity to meet and hear the inventor of the free electron laser, John Madey, who delivered the keynote address Sadly, this was also the last time most of the participants met him; John Madey passed away just over a year after the symposium, on 5 July 2016. 
Acknowledgments: The Nobel Symposium on Free Electron Laser Research was Number 158 of all Symposia since the start in 1965. It was financially supported by the Nobel Foundation and the Knut and Alice Wallenberg Foundation. The FEL consortium between Stockholm University, Uppsala University, and the Royal Institute of Technology supported the participation of about 30 younger researchers, and observers from Belarus and Ukraine.

Conflicts of Interest: The author declares no conflict of interest.

(c) 2017 by the author. Licensee MDPI, Basel, Switzerland. This article is an open access article distributed under the terms and conditions of the Creative Commons Attribution (CC BY) license (http:/ / creativecommons.org/licenses/by/4.0/). 